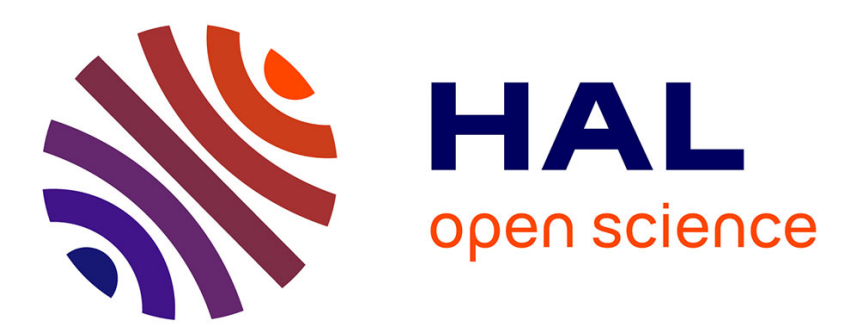

\title{
Optimization of Early Voltage for Cooled SiGe HBT Precision Current Sources
}

\author{
A. Joseph, J. Cressler, D. Richey
}

\section{To cite this version:}

A. Joseph, J. Cressler, D. Richey. Optimization of Early Voltage for Cooled SiGe HBT Precision Current Sources. Journal de Physique IV Proceedings, 1996, 06 (C3), pp.C3-125-C3-129. 10.1051/jp4:1996319 . jpa-00254237

\section{HAL Id: jpa-00254237 https://hal.science/jpa-00254237}

Submitted on 1 Jan 1996

HAL is a multi-disciplinary open access archive for the deposit and dissemination of scientific research documents, whether they are published or not. The documents may come from teaching and research institutions in France or abroad, or from public or private research centers.
L'archive ouverte pluridisciplinaire HAL, est destinée au dépôt et à la diffusion de documents scientifiques de niveau recherche, publiés ou non, émanant des établissements d'enseignement et de recherche français ou étrangers, des laboratoires publics ou privés. 


\title{
Optimization of Early Voltage for Cooled SiGe HBT Precision Current Sources
}

\author{
A.J. Joseph, J.D. Cressler and D.M. Richey \\ Electrical Engineering Department, 200 Broun Hall, Auburn University, Auburn, AL 36849-5201, U.S.A.
}

\begin{abstract}
The influence of Ge profile shape on the temperature characteristics of two key analog transistor parameters, Early voltage $\left(V_{A}\right)$ and current gain-Early voltage product $\left(\beta V_{A}\right)$, in SiGe HBTs have been studied over the temperature range of $300 \mathrm{~K}-77 \mathrm{~K}$ using SCORPIO, a transistor simulation tool calibrated to measured data [1]. A new version of SPICE that accounts for the temperature dependence of $V_{A}$ was used to model the various SiGe HBTs simulated and thereby evaluate the cryogenic performance of SiGe HBT precision current sources, which are strongly influenced by the variations in both $\beta$ and $V_{A}$. Results clearly indicate that the cryogenic performance of these SiGe current sources can be significantly improved by using a graded Ge profile instead of a constant Ge profile in the base region of the HBT.
\end{abstract}

\section{INTRODUCTION}

Unlike Si BJTs, which suffer performance degradation at low-temperatures due to heavy-doping and freezeout effects, bandgap-engineered SiGe HBTs are naturally suited for cryogenic applications [2]. Small fractions of Ge introduced into the base region of a SiGe HBT cause bandgap offsets that aid the minority carrier injection and its transport through the base region, allowing for the design of highperformance bipolar transistors. Since most of the useful transistor parameters are thermally activated by the amount of bandgap offset introduced in the base region of the SiGe HBT, it is expected that the cryogenic performance of these transistors will be far superior to its room-temperature performance.

Among the many $d c$ transistor parameters that need to be optimized for analog applications, the most important ones are $\beta$ and $V_{A}$. The $\beta$ of a transistor signifies the amount of output current $\left(I_{C}\right)$ available for a given input current $\left(I_{B}\right)$, whereas, the $V_{A}$ of a transistor accounts for its output resistance. In conventional $\mathrm{Si}$ BJTs, $\beta$ is inversely proportional to the base doping concentration and $\mathrm{V}_{\mathrm{A}}$ is directly proportional to the base doping. Therefore, it is difficult to simultaneously improve both $\beta$ and $V_{A}$ in $S i$ $\mathrm{BJTs}$, and hence $\beta V_{\mathrm{A}}$ is considered a key figure-of-merit for analog transistors.

It can be shown mathematically that the improvement in $V_{A}$ and $\beta V_{A}$ in SiGe HBTs compared to that in a similarly constructed $\mathrm{Si} \mathrm{BJT}$ is [3]:

$$
\begin{aligned}
& \frac{V_{A, \text { SiGe }}}{V_{A, S i}}=\frac{\exp \left(\Delta E_{g, G e}(\text { grade }) / k T\right)-1}{\Delta E_{g, G e}(\text { grade }) / k T} \\
& \frac{\beta V_{A, S i G e}}{\beta V_{A, S i}}=\eta \gamma \exp \left(\Delta E_{g, G e}\left(x=W_{B}\right) / k T\right)
\end{aligned}
$$

Here, $\Delta \mathrm{E}_{\mathrm{g}, \mathrm{Ge}}($ grade $)=\Delta \mathrm{E}_{\mathrm{g}, \mathrm{Ge}}\left(\mathrm{x}=\mathrm{W}_{\mathrm{B}}\right)-\Delta \mathrm{E}_{\mathrm{g}, \mathrm{Ge}}(\mathrm{x}=0)$, represents the bandgap grading introduced into the base region of a SiGe HBT. Also, $\Delta \mathrm{E}_{\mathrm{g}, \mathrm{Ge}}(\mathrm{x}=0)$ and $\Delta \mathrm{E}_{\mathrm{g}, \mathrm{Ge}}\left(\mathrm{x}=\mathrm{W}_{\mathrm{B}}\right)$ are the Ge-induced bandgap offsets at 
the emitter-base (EB) and collector-base (CB) depletion edges in the base region, respectively. Parameters $\eta$ and $\gamma$ represent the ratio of position-averaged minority carrier mobility in the base region of a SiGe HBT compared to that in a Si BJT, and the ratio of position-averaged density-of-states in the base region of a SiGe HBT compared to that in a Si BJT, respectively. Equations (1) and (2) indicate that both $\mathrm{V}_{\mathrm{A}}$ and $\beta \mathrm{V}_{\mathrm{A}}$ in SiGe HBTs can be improved by increasing the bandgap grading in the base region. It is also clear that by cooling, an exponential increase in both of these parameters can be obtained for a SiGe HBT when compared to a similarly constructed Si BJT. Previous studies have shown that the experimental data obtained by cooling advanced UHV/CVD SiGe and Si transistors are in agreement with these theoretical expectations [4].

A recently developed 1-D transistor simulator (SCORPIO), calibrated to SiGe HBT data over a wide temperature range, has also confirmed the exponential temperature dependence for both $V_{A}$ and $\beta V_{A}$ in graded Ge profile SiGe HBTs [1]. SCORPIO uses the SIMS doping profile of a transistor as its input to generate the terminal characteristics of the transistor. Advanced parameter models for minority and majority carrier mobilities, density-of-states, and carrier freezeout are incorporated into SCORPIO and each model takes into account the differences between the $\mathrm{Si}$ and $\mathrm{SiGe}$ material systems.

\section{RESULTS AND DISCUSSIONS}

Experiment, theory, and simulation results indicate that by introducing a graded Ge profile into the base region of a SiGe HBT one can exponentially enhance the cryogenic performance of the SiGe HBTs. However, the maximum amount of Ge that can be introduced into any epitaxial SiGe layer must comply with the well-known thermodynamic stability constraint [5], as depicted in Fig. 1. Stiffler et al.'s [6] stability curve shown in the same figure is an empirical result for the critical thickness in strained UHV/CVD SiGe epitaxial films. For any given effective thickness of the epitaxial SiGe film, the film will be unconditionally stable (defect free) if the amount of Ge introduced into the film is below the critical limit (lower left region of the figure) and for Ge content above this critical limit a metastable film will result.

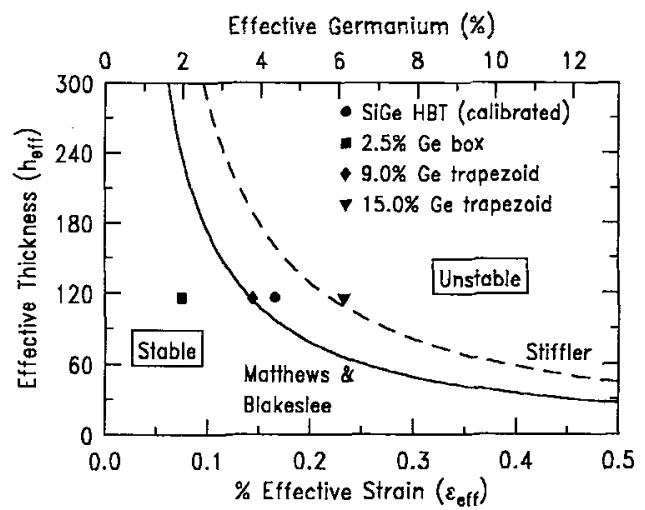

Figure 1. Thermodynamic stability constraint applicable to SiGe epitaxial films.

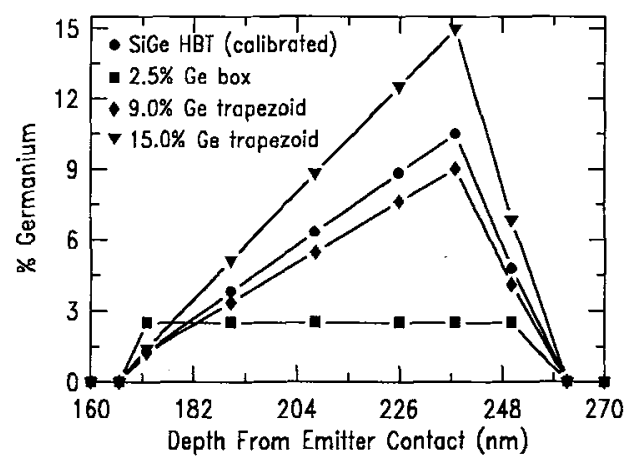

Figure 2. Germanium profiles with varying Ge grading in the neutral base and approximately similar Ge content at the EB depletion edge.

In the present study, in order to quantify the influence of Ge profile shape on the temperature characteristics of precision SiGe current sources, we began by calibrating SCORPIO to measured results for $\beta$ and $V_{A}$ in SiGe HBTs. Device characteristics of an advanced UHV/CVD epitaxial Si- and SiGe- 
base technology [7] were measured from $300 \mathrm{~K}$ to $140 \mathrm{~K}$. SIMS data of the SiGe HBT was used as a starting point for the calibration of SCORPIO to the measured results. The Ge profile shown as a solid circle in Fig. 2 was the final calibrated Ge profile shape obtained for the simulated SiGe HBT, and showed consistent agreement with all measured $d c$ and $a c$ characteristics of SiGe HBT over the entire temperature range. Reasonable agreement between the simulation and the measured $d c$ characteristics of the Si BJT was also achieved over this temperature range by using the calibrated SIMS profile, with the Ge profile simply removed.

Two different situations in the variation of the Ge profile shape for a fixed effective SiGe film thickness were considered in the present study: (a) constant integrated Ge content (or constant stability), and (b) variable Ge content. In case (a), the profiles considered varied from a $5.5 \%$-box profile to a $11.0 \%$-triangular profile, with all profiles having the same integrated Ge content as the calibrated SiGe HBT profile (see Fig. 3. inset). Fig. 3 shows the simulation results for the ratio of both $V_{A}$ and $\beta V_{A}$ in SiGe HBTs when compared to a similarly constructed Si BJT, obtained at $300 \mathrm{~K}$ and $77 \mathrm{~K}$. As expected, the box profile shows no improvement in $V_{A}$ with cooling, but, the triangular profile shows a strong increase in $V_{A}$ at $77 \mathrm{~K}$ when compared to the $300 \mathrm{~K}$ value. The increase in $\beta V_{A}$ for the box profile SiGe $\mathrm{HBT}$ at $77 \mathrm{~K}$ when compared to $300 \mathrm{~K}$ is because of the exponential increase in $\beta$ due to the presence of significant $\Delta \mathrm{E}_{\mathrm{g}, \mathrm{Ge}}(\mathrm{x}=0)$. In triangular profile SiGe HBT, however, this increase is due to the exponential increase in both $\beta$ and $V_{A}$. It is clear, therefore, that for analog applications requiring SiGe HBTs, a triangular Ge profile will maximize both $V_{A}$ and $\beta V_{A}$ for a given integrated Ge content.

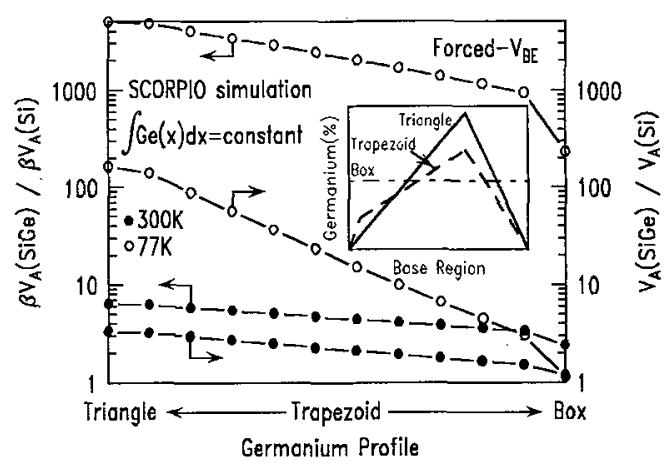

Figure 3. SCORPIO simulation results for the ratio of $V_{A}$ and $\beta V_{A}$ in SiGe HBT compared to a Si BJT, obtained at $300 \mathrm{~K}$ and $77 \mathrm{~K}$. The Ge profile used in the simulation was varied from a box profile to a triangular profile, keeping the integrated Ge content fixed.

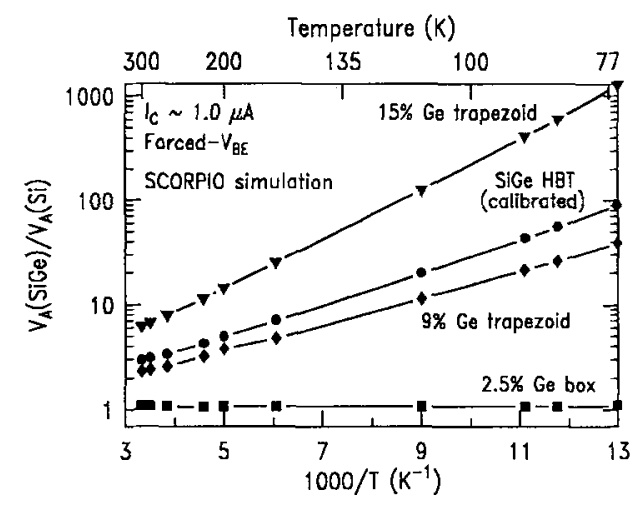

Figure 4. The ratio of $\mathrm{V}_{\mathrm{A}}$ in SiGe HBTs compared to a $\mathrm{Si}$ $\mathrm{BJT}$, as a function of temperature. The integrated $\mathrm{Ge}$ in the base region is varied to increase the bandgap grading, keeping $\Delta \mathrm{E}_{\mathrm{g}, \mathrm{Ge}}(\mathrm{x}=0)$ approximately the same.

In case (b), the integrated Ge content in the base region was varied by changing the Ge grading and maintaining the Ge content in the EB depletion edge approximately the same. We have considered 3 different Ge profiles (see Fig. 2): 2.5\%-box, 9\%-trapezoid, and 15\%-trapezoid, that fall into various regions of the stability space due to their different Ge concentrations (Fig. 1). By maintaining a similar value of Ge concentration at the EB boundary in all of the profiles, the temperature characteristics of $\beta$ is expected to be similar in all cases. However, the differences in the Ge grading is expected to strongly impact the temperature characteristics of $V_{A}$ in these transistors. Fig. 4 shows the simulated results for $V_{A}$ as a function of reciprocal temperature for SiGe HBTs compared to a similarly processed $\mathrm{Si} \mathrm{BJT}$. As 
expected, the box profile does not enhance the $V_{A}$, but the $15 \%$ Ge trapezoidal profile has almost $1300 \times$ improvement in $\mathrm{V}_{\mathrm{A}}$ at $77 \mathrm{~K}$ compared to a $\mathrm{Si} \mathrm{BJT}$.

Precision current sources, commonly used in high-precision analog circuits, are required to maintain constant output current for large changes in output voltages, and thus require large $R_{\text {out }}$. Since the $R_{\text {out }}$ of such precision circuits is controlled by the $V_{A}$ (or $\beta V_{A}$ ) of the output transistor, it is expected that the use of Ge grading in SiGe HBTs will have a strong impact on the temperature characteristics of such high-precision $\mathrm{SiGe}$ current sources. In order to quantify this effect, we have modified the conventional SPICE program (PSPICE) by introducing two new parameters, XTVA and XTVB, to accurately model the temperature dependence of $V_{A}$ and $V_{B}$ (inverse Early voltage) in SiGe HBTs. Figs. 5 and 6 show the close agreement between the modified SPICE model and the measured $d c$ characteristics of both Si and SiGe transistors. Calibrated SPICE models were also constructed for each of the 3 simulated SiGe HBTs considered in this study.

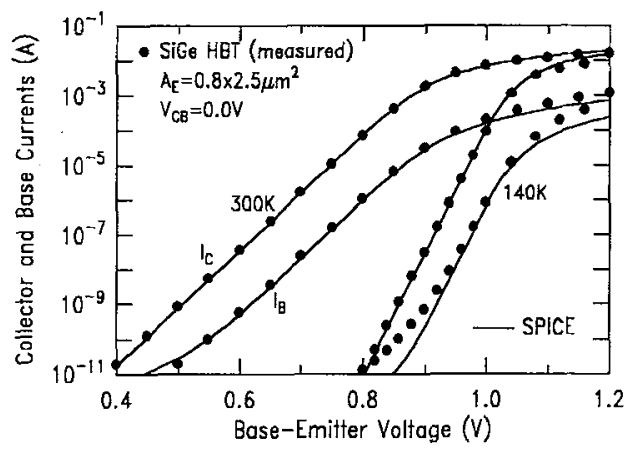

Figure 5. Gummel characteristics for the SiGe HBT measured at $300 \mathrm{~K}$ and $140 \mathrm{~K}$ compared to that obtained from a calibrated SPICE model.

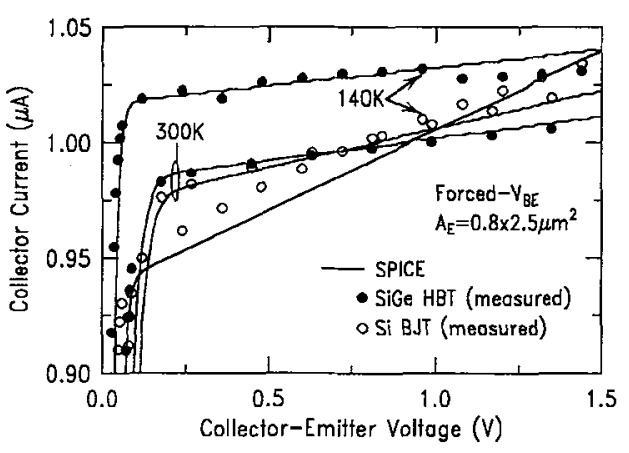

Figure 6. Output characteristics for both $\mathrm{SiGe}$ and $\mathrm{Si}$ transistors measured at $300 \mathrm{~K}$ and $140 \mathrm{~K}$ compared with the results obtained from modified SPICE models.

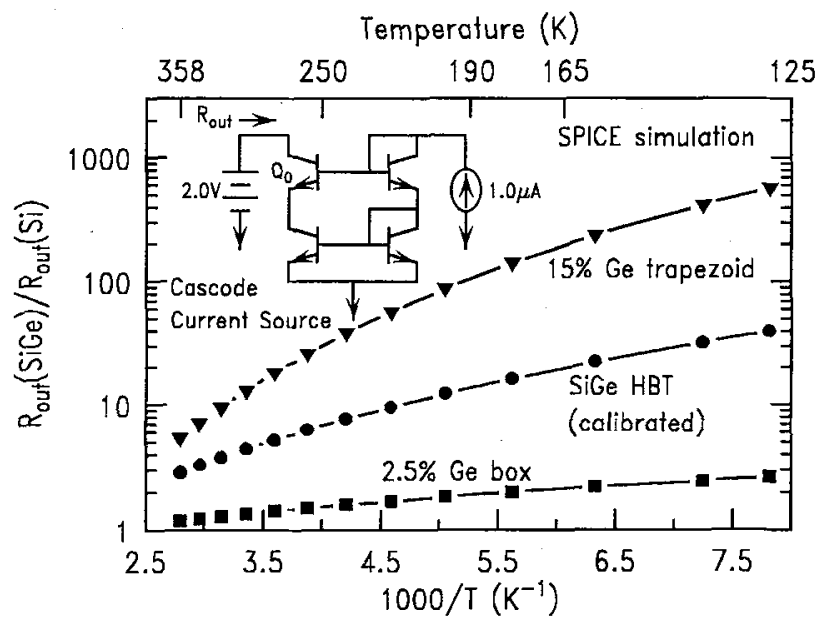

Figure 7. Ratio of $\mathrm{R}_{\text {out }}$ of a SiGe HBT cascode current source to that of a Si circuit, as a function of reciprocal temperature. The inset shows the circuit topology for a cascode current source. 
In this study, we have considered a cascode current source as an example of a high precision current source in order to compare the enhancement in $\mathbf{R}_{\text {out }}$ of a SiGe HBT circuit when compared to that of a Si BJT circuit. Cascode current sources, as shown in Fig. 7, employ negative feedback to increase its $\mathrm{R}_{\text {out }}$ (proportional to the $\beta V_{A}$ of $Q_{0}$ ). Fig. 7 shows the ratio of $R_{\text {out }}$ of a SiGe HBT current source when compared to that obtained from a similarly constructed Si BJT current source, over a wide temperature range. Observe that the current source employing a box profile SiGe HBT shows only a slight increase in its performance at low temperatures due to the increase in $\beta$ with cooling. However, both current sources using SiGe HBTs with Ge trapezoids show a significant increase in their $\mathrm{R}_{\text {out }}$ at low temperatures compared to their Si counterparts. This enhancement is mainly due to the increase in $V_{A}$ by introducing large bandgap grading in the base region using $\mathrm{Ge}$.

\section{CONCLUSIONS}

Using SCORPIO and a new version of SPICE, we have investigated the influence of Ge grading on the temperature characteristics of a high-precision cascode current source. Results clearly indicate that the box profile SiGe HBT only provide marginal improvement in the $R_{\text {out }}$ of the current source, whereas a graded Ge profile SiGe HBT yields a significantly larger $R_{\text {out }}$ at all temperatures. Our studies indicate that for stable SiGe films in SiGe HBTs, any addition of Ge in the form of grading in the base region will significantly improve the low-temperature characteristics of both $V_{A}$ and $\beta V_{A}$ and hence greatly improve the $\mathrm{R}_{\text {out }}$ of cooled SiGe HBT precision current sources. It was also shown that for any given integrated Ge content in a stable SiGe film, the maximum impact of both $V_{A}$ and $\beta V_{A}$ can be attained by introducing a triangular Ge profile in the base region of SiGe HBTs as opposed to any other profile shape. Thus, for cryogenically operated high precision SiGe HBT current sources, strongly graded triangular Ge profile SiGe HBTs will be optimum.

\section{Acknowledgments}

This work was supported by The Naval Research Laboratory and The US Army Space and Strategic Defense Command under contract \# N00014-95-1-G002, and by The Office of Naval Research under J.D. Cressler's ONR Young Investigator Award, grant \# N00014-94-1-0690. The samples were fabricated at the IBM Research Division, Yorktown Heights, NY. The contributions of D.L. Harame, R.C. Jaeger, C. Ellis, B. Ansley, S. Lathams, G. Bradford, S. Mathew, K. Jayanarayan, and J. Roldan, to this work are gratefully acknowledged.

\section{References}

[1] D.M. Richey, J.D. Cressler, and R.C. Jaeger, J. de Physique IV, Volume 4 (1994) 127-132.

[2] J.D. Cressler, J. de Physique IV, Volume 4 (1994) 101-110.

[3] E.J. Prinz and J.C. Sturm, IEEE Electron Device Letters, Volume 12 (1991) 661-663.

[4] A.J. Joseph, J.D. Cressler, D.M. Richey, and D.L. Harame, Proc. of the 1995 ECS Symp. on LowTemperature Electronics and High-Temperature Superconductivity, 211-220.

[5] J. Matthews and A. Blakeslee, J. Crystal Growth, Volume 27 (1974) 118-125.

[6] S.R. Stiffler, J.H. Comfort, C.L. Stanis, D.L. Harame, E.de Frésart, and B.S. Meyerson, J. Applied Physics, Volume 70(3) (1991) 1416-1420.

[7] D.L. Harame, J.H. Comfort, J.D. Cressler, E.F. Crabbé, J.Y.-C. Sun, B.S. Meyerson, and T. Tice, IEEE Transactions on Electron Devices, Volume 42(3) (1995) 469-482. 